\title{
EGA-Net: Endüstri 4.0 ve Dijital Dönüşüm Döneminde Üretim Çalışanlarının Yüz İfadesi, Yaş ve Cinsiyetlerinin Derin Öğrenme Yöntemleri ile Analizi
}

\author{
EGA-Net: Analysis of Facial Expression, Age and Gender of \\ Manufacturing Employees with Deep Learning Methods in the Industry \\ 4.0 and Digital Transformation Era \\ Caglar Gurkan $^{* 1}$ (D) , Merih Palandoken ${ }^{1,2,3}$
}

1Elektrik - Elektronik Mühendisliği Bölümü, İzmir Katip Çelebi Üniversitesi Üniversitesi, İzmir, Türkiye

${ }^{2}$ Yapay Zeka ve Veri Bilimi Uygulama ve Araştırma Merkezi, İzmir Katip Çelebi Üniversitesi Üniversitesi, İzmir, Türkiye

${ }^{3}$ Akıllı Fabrika Sistemleri Araştırma ve Uygulama Merkezi, İzmir Katip Çelebi Üniversitesi

Üniversitesi, İzmir, Türkiye

(caglar.gurkan@outlook.com, merih.palandoken@ikcu.edu.tr)

Özetçe- Günümüzde insanların yüz ifadeleri, yaşları ve cinsiyetlerinin bilgisayarla analizi, insanmakine etkileşimi araştırma alanındaki teknolojik gelişmelerle birlikte önemli bir araştırma konusu haline gelmiştir. Bu analizin sağlanması için manuel olarak özellik çıkarımına ihtiyaç duymayan evrişimli sinir ağları algoritmaları sıklıkla kullanılmaktadır. Bu çalışmada, üretim çalışanlarının yüz ifadesi, yaş ve cinsiyetlerinin analiz edilmesi için CK+ ve UTKFace olmak üzere iki farklı veri seti kullanılmıştır. Bu veri setleri dört farklı yeni evrişimli sinir ağları mimari tasarımlarının eğitiminde kullanılmıştır. En iyi sınıflandırma performansını elde eden evrişimli sinir ağları mimari tasarımı EGANet olarak isimlendirilmiştir. Sonrasında EGA-Net'e ait ağırlık dosyaları OpenCV kütüphanesi ile birlikte kullanılmıştır. Böylelikle yüz ifadesi, yaş ve cinsiyet gerçek zaman olarak analiz edilmiştir.

Anahtar Kelimeler: Evrişimli sinir ağları, EGA-Net, yüz ifadesi analizi, yaş analizi, cinsiyet analizi

\footnotetext{
Abstract - Nowadays, analysis of people's facial expressions, age, and gender by computer has become a considerable research topic together with technological advances in the area of human-machine interaction research. To provide this analysis, convolutional neural network algorithms that do not need manual feature extraction are widely used. In this study, two different data sets, CK+ and UTKFace, have been used to analyze the facial expression, age, and gender of manufacturing employees. These data sets have been used in the training of four different novel convolutional neural networks architecture designs. The convolutional neural network architecture design that achieves the best classification performance has been called as EGA-Net. After that, the weight files of the EGA-Net have been used together with the OpenCV library. Thus, facial expression, age, and gender have been analyzed in real-time.
} 
Keywords: Convolutional neural networks, EGA-Net, facial expression analysis, age analysis, gender analysis

\section{Giriş}

Yaş, cinsiyet ve yüz ifadesinin analizinin sağlanması birçok kullanım alanında önem arz etmektedir. Bu kullanım alanlarına örnek olarak sosyal davranış analizi, kimlik doğrulama, müşteri analizi, çalışan analizi, kalabalık davranış analizi, çevrimiçi reklam ve ürün önerisi verilebilmektedir. Yaş, cinsiyet ve yüz ifadesinin analizi bu derecede önemli olmasına rağmen zorlu bir mühendislik problemi olarak nitelendirilebilmektedir. Yaş, cinsiyet ve yüz ifadelerinin analizi için yürütülen çalışmalarda kullanılan yöntemlerin ilk ve en önemli basamağı öznitelik çıkarımı olarak işaret edilmektedir. Öznitelik çıkarımı ile birlikte doğru öznitelik seçimi, veri setindeki görsellerin yüksek başarım oranı ile sınıflandırılmasını sağlamaktadır. Bu yüksek başarım oranını mümkün kılan ve günümüzde öznitelik çıkarımında sıklıkla kullanılan yöntem evrişimli sinir ağlarıdır (ESA). ESA'lar geleneksel ve manuel öznitelik çıkarımına ihtiyaç duymaksızın görsellerden özniteliklerin elde edilmesini sağlamaktadır.

Çalışmanın temel amacı endüstrideki dijital dönüşüme katkıda bulunulmasıdır. Bu nedenle, üretim çalışanlarının yaş, cinsiyet ve yüz ifadeleri gerçek zamanlı olarak analiz edilmiştir. Analiz sürecinin sağlanması amacıyla çalışmada UTKFace veri seti yaş ve cinsiyet sınıflandırma görevinde CK+ veri seti yüz ifadesi sınıflandırma görevinde olmak üzere iki farklı veri seti, geliştirilen dört farklı ESA mimari tasarımının eğitiminde kullanılmıştır. En iyi sınıflandırma performansını elde eden ESA mimari tasarımı EGA-Net olarak isimlendirilmiş ve literatüre kazandırılmıştır.

Çalışmanın geri kalan bölümü şu şekilde düzenlenmiştir; 2. bölümde literatürdeki benzer çalışmalar aktarılmıştır. 3. bölümde kullanılan veri setlerinin özellikleri ve ön işleme süreçleri aktarıldıktan sonra çalışmada önerilen ESA mimari tasarımları katman detayları ve eğitim aşamaları ile birlikte tanıtılmış ve ESA mimari tasarımlarının performanslarının karşılaştırılmasında kullanılan metrisler formülleri ile sunulmuştur. 4. bölümde kullanılan ESA mimari tasarımları ile elde edilen sonuçlar analiz edilmiş, yorumlanmış ve karşılaştırılmıştır, 5. bölümde ise çalışma ile igili son bilgiler sunulmuştur.

\section{2. İlgili Çalışmalar}

Literatürdeki benzer önceki çalışmalar bu bölümde aktarılmaktadır.

Levi ve Hassner tarafından yaş ve cinsiyet analizi için yapılan çalışmada ESA mimari tasarımı kullanılmıştır (Levi ve Hassncer, 2015). Kullanılan bu ESA mimari tasarımı yalın bir yapı ile oluşturulurken öznitelik çıkarımı için birbirini takip eden beş adet konvolüsyon katmanı kullanılmıştır. Abdolrashidi ve ark. tarafından yapılan çalışmada yaş ve cinsiyet analizi görevleri için UTKFace veri seti kullanılmıştır (Abdolrashidi, Minaei, Azimi ve Minaee, 2020). Araştırmacılar, yaşın sınıflandırılması için veri setindeki görselleri toplam sekiz yaş aralığı olacak şekilde etiketlemişlerdir. Çalışmadaki sınıflandırma görevlerinde ise ResNet ESA mimarı tasarımını kullanmışlardır. Ozbulak ve ark. tarafından yapılan çalışmada yaş ve cinsiyet analizi görevleri için AlexNet ve VGG ESA mimari tasarımlarına ait ağırlık dosyaları transfer öğrenme yönteminde kullanılmıştır (Özbulak, Aytar ve Ekenel, 2016). Söylemez ve Ergen yaptıkları çalışmada kızgın, iğrenme, korku, mutlu, üzgün, şaşkın ve nötr olmak üzere toplam yedi sinıftan oluşan FER2013 veri setini kullanarak yüz ifadelerini analiz etmişlerdir (Söylemez ve Ergen, 2020). Kullandıkları ESA mimari tasarımları ise VGG16, VGG16bnorm, Xception, ResNet50V1, ResNet50V2, InceptionV1, InceptionV3, MobileNetV1 ve MobileNetV2 şeklindedir. Bu ESA mimari tasarımları içersinde en iyi sınıflandırma performansı ise \%65.8'lik doğruluk oranı ile InceptionV1 elde etmiştir. Pitaloka ve ark. yaptıkları çalışmada altı farklı yüz ifadesini içeren bir veri setini kullanmışlardır (Pitaloka, Wulandari, Basaruddin ve Liliana, 2017). Bu veri setinde yer alan görsellere yeniden boyutlandırma, kırpma ve normalleştirme gibi çeşitli ön işleme yöntemlerini uygulamışlardır. Daha sonra ise ön işleme yöntemleri uygulanan bu görselleri ESA mimari tasarımına girdi olarak vermişlerdir. 


\section{Materyal ve Yöntem}

Çalışmada kullanılan materyaller ve yöntemler; veri setleri ve veri ön işleme, ESA modelleri ve eğitim aşaması, perform değerlendirme metrikleri olmak üzere üç alt başlık altında bu bölümde sunulmuştur.

\subsection{Veri Setleri ve Veri Ön İşleme}

Çalışmada iki farklı veri seti kullanılmıştır. Bu veri setlerinden biri yüz ifadelerinin sınıflandırılması görevinde kullanılırken diğeri yaşın ve cinsiyetin sınıflandırılması görevlerinde kullanılmıştır.

Yüz ifadelerinin sınıflandırılması için CK+ veri seti kullanılmıştır (“CKPLUS I Kaggle," n.d.). Bu veri setinde kızgın, küçümseme, iğrenme, korku, mutlu, üzgün ve şaşkın olmak üzere 7 etikette sırasıyla 135, 54, 177, 75, 207, 84 ve 249 görsel bulunmaktadır. Bu etiketlerdeki örnek görüntüler Şekil 1'de gösterilmiştir. Veri setindeki görseller 200×200 piksel olarak yeniden boyutlandırılırken, görsellerin \%80'i eğitim, \%20'si doğrulama için kullanılmıştır.

Yaş ve cinsiyet sınıflandırılması görevinde UTKFace veri seti kullanılmıştır ("UTKFace I Kaggle," n.d.). Bu veri seti 0 ile 116 yaş aralığındaki kişilere ait görüntülere ek olarak yaş, cinsiyet ve etnik köken gibi açıklayıcı bilgileri içerisinde bulundurmaktadır. Bu veri setine ait örnek görüntüler Şekil 2'de gösterilmiştir. Ek olarak veri setine ait yaş ve cinsiyet dağılımı sırasıyla Şekil 3 (a) ve (b)'de gösterilmiştir. Veri setindeki görüntüler 200x200 piksel olarak yeniden boyutlandırılırken, yaş sınıflandırması yapabilmek için veri setindeki görüntüler 0-30 yaş aralığı, 31-45 yaş aralığı, 46-60 yaş aralığı ve +60 yaş olmak üzere dört sınıfta etiketlenmiştir. Ek olarak cinsiyet sınıflandırması yapabilmek için ise veri setindeki görseller kadın ve erkek olmak üzere iki sınıfta etiketlenmiştir. Veri setindeki görsellerin \%80'i eğitim, \%20'si doğrulama için kullanılmıştır.

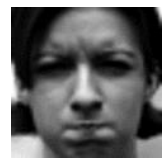

(a)

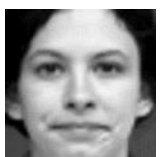

(b)

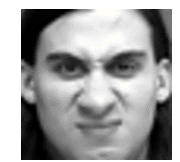

(c)

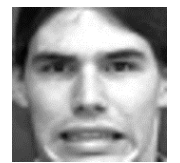

(d)

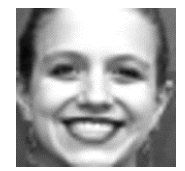

(e)

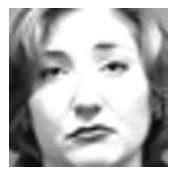

(f)

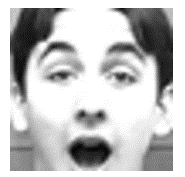

(g)

Şekil 1. Yüz ifadesinin sınıflandırılmasında kullanılan veri setinden örnek görüntüler (a) kızgın, (b) küçümseme, (c) iğrenme, (d) korku, (e) mutlu, (f) üzgün ve (d) şaşkın
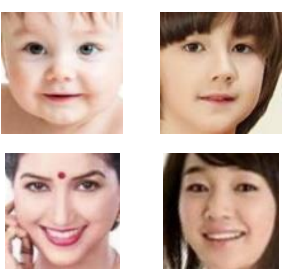
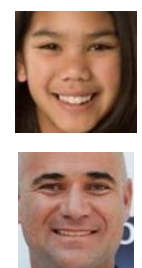
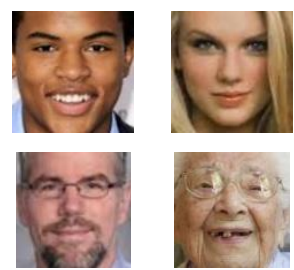

Şekil 2. Yaş ve cinsiyet sınıflandırılmasında kullanılan veri setinden örnek görüntüler

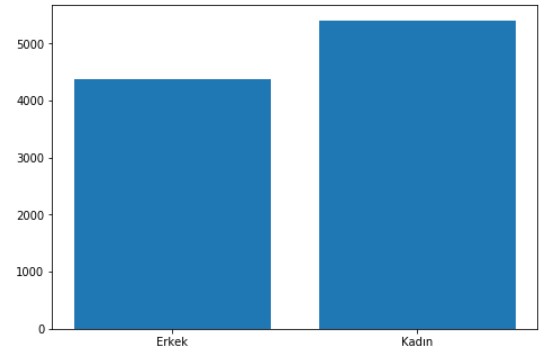

(a)

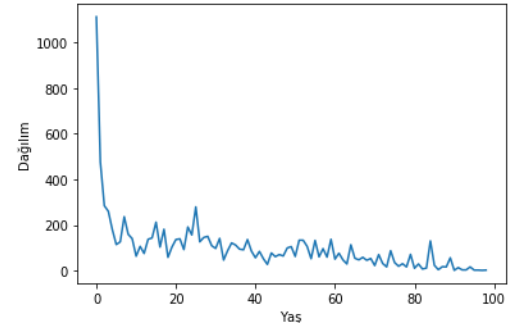

(b)

Şekil 3. Veri setine ait (a) cinsiyet dağılımı, (b) yaş dağılımı 


\subsection{ESA Modelleri ve Eğitim Aşaması}

Çalışmada dört farklı ESA mimari tasarımı önerilmiştir. ESA mimari tasarımlarına ait katman detayları, hiperparametreleri ile birlikte bu bölümde aktarılmıştır. Ayrıca geliştirilen bu ESA mimari tasarımlarının eğitim aşamasına ait detaylar da bu bölümde sunulmuştur.

ESA Mimari Tasarımı 1: Giriş görüntüleri, iki konvolüsyon katmanı ve bu katmanları sırası ile takip eden toplu normalleştirme ve maksimum havuzlama katmanlarından oluşan iki farklı bloğa girdi olarak verilmiştir. Bu iki farklı blokta kullanılan maksimum havuzlama katmanlarına ait hiperparametreler kernel boyutu 2, adım sayısı 2 ve dolgusu uygun olarak seçilmiştir. Bu bloklardan birincisinde özellik çıkarımı için kullanılan iki adet konvolüsyon katmanının hiperparametreleri; filtre sayısı, adım sayısı, dolgusu ve aktivasyon fonksiyonu sabit olarak sırasıyla 16, 1, uygun ve ReLU olarak kullanılırken kernel boyutları sırasıyla ilk konvolüsyon katmanı için 7 ve ikinci konvolüsyon katmanı için 3 olarak seçilmiştir. Bu bloklardan ikincisinde özellik çıkarımı için kullanılan iki adet konvolüsyon katmanının hiperparametreleri; filtre sayısı, kernel boyutu, adım sayısı, dolgusu ve aktivasyon fonksiyonu sabit olarak sırasıyla 16, 5, 1, uygun ve ReLU olarak seçilmiştir. Sonrasında bu iki blok ile aynı boyutta elde edilen özellik haritaları matematiksel operatör aracılığıyla eklenmiş ve elde edilen çıkış iki seri bloğa girdi olarak verilmiştir. Bu bloklar aynı hiperparametrelere sahip iki konvolüsyon katmanı ve bu katmanları sırası ile takip eden toplu normalleştirme ve maksimum havuzlama katmanlarından oluşmaktadır. Bu iki blokta kullanılan maksimum havuzlama katmanlarına ait hiperparametreler kernel boyutu 2, adım sayısı 2 ve dolgusu uygun olarak seçilmiştir. Bu bloklarda özellik çıkarımı için kullanılan iki adet konvolüsyon katmanının hiperparametreleri; filtre sayısı, kernel boyutu, adım sayısı, dolgusu ve aktivasyon fonksiyonu sabit olarak sirasiyla 32, 3, 1, aynı ve ReLU olarak seçilmiştir. Son olarak, özellik çıkarımı için kullanılan katmanlardan elde edilen özellik haritası birleştirilmiş ve sonrasında tek boyutta düzleştirilmiştir. Bu mimari tasarım Şekil 4'te gösterilmiştir.

ESA Mimari Tasarımı 2: Bu mimari tasarımda, ESA mimari tasarımı 1'den farklı olarak elde edilen özellik haritasının birleştirilmesinden sonra filtre sayısı, kernel boyutu, adım sayısı, dolgusu ve aktivasyon fonksiyonu sırasıyla 32, 3, 1, aynı ve ReLu olan konvolüsyon katmanının ardından toplu normalleştirme ve kernel boyutu 2, adım sayısı 2 ve dolgusu uygun olan maksimum havuzlama katmanlarının sırasıyla kullanılması, sonrasında ise elde edilen özellik haritasının tek boyutta düzleştirilmesidir. Bu mimari tasarım Şekil 5'te gösterilmiştir.

ESA Mimari Tasarımı 3: Giriş görüntüleri üç farklı bloğa girdi olarak verilmiştir. Bu bloklardan ikisi, iki konvolüsyon katmanı ve bu katmanları sırası ile takip eden toplu normalleştirme ve maksimum havuzlama katmanlarından oluşmaktadır. Maksimum havuzlama katmanlarına ait hiperparametreler kernel boyutu 2, adım sayısı 2 ve dolgusu uygun olarak seçilmiştir. Üçüncü blok ise iki konvolüsyon katmanı, bu katmaları takip eden toplu normalleştirme katmanları ve bloğun çıkışında yer alan maksimum havuzlama katmanından oluşmaktadır. Bu bloklardan birincisinde özellik çıkarımı için kullanılan iki adet konvolüsyon katmanının hiperparametreleri; filtre sayısı, adım sayısı, dolgusu ve aktivasyon fonksiyonu sabit olarak sirasiyla 16, 1, uygun ve ReLU olarak kullanilırken kernel boyutları sırasıyla ilk konvolüsyon katmanı için 7 ve ikinci konvolüsyon katmanı için 3 olarak seçilmiştir. Bu bloklardan ikincisinde özellik çıarımı için kullanılan iki adet konvolüsyon katmanının hiperparametreleri; filtre sayısı, kernel boyutu, adım sayısı, dolgusu ve aktivasyon fonksiyonu sabit olarak sırasıyla 16, 5, 1, uygun ve ReLU olarak seçilmiştir. Bu bloklardan üçüncüsünde özellik çıkarımı için kullanılan iki adet konvolüsyon katmanının hiperparametreleri; ilk konvolüsyon katmanı için filtre sayısı, kernel boyutu, adım sayısı, dolgusu ve aktivasyon fonksiyonu sirasiyla 16, 7, 2, uygun ve ReLU olarak seçilirken, ikinci konvolüsyon katmanı için filtre sayısı, kernel boyutu, adım sayısı, dolgusu ve aktivasyon fonksiyonu sırasıyla 16, 3, 1, uygun ve ReLU olarak seçilmiştir. Son olarak, özellik çıkarımı için kullanılan katmanlardan elde edilen özellik haritası birleştirilmiş ve sonrasında tek boyutta düzleştirilmiştir. Bu mimari tasarım Şekil 6'da gösterilmiştir.

ESA Mimari Tasarımı 4: Bu mimari tasarımda, ESA mimari tasarımı 3'ten farklı olarak elde edilen özellik haritasının birleştirilmesinden sonra filtre sayısı, kernel boyutu, adım sayısı, dolgusu ve 
aktivasyon fonksiyonu sırasıyla 32, 3, 1, aynı ve ReLu olan konvolüsyon katmanının ardından toplu normalleştirme ve kernel boyutu 2, adım sayısı 2 ve dolgusu uygun olan maksimum havuzlama katmanlarının sırasıyla kullanılması, sonrasında ise elde edilen özellik haritasının tek boyutta düzleştirilmesidir. Bu mimari tasarım Şekil 7'de gösterilmiştir.

ESA mimari tasarımı 2 ve 4 için birleştirme katmanından sonra konvolüsyon ve havuzlama katmanlarının kullanımı ile düzleştirme katmanından sonra elde edilen matrisin boyutunun küçültülmesi amaçlanmıştır. Böylelikle ESA modellerinin eğitim süresinin kısaltılması sağlanmıştır.

Önerilen ESA Mimari Tasarımlarının Eğitim Aşaması: Optimizasyon algoritması olarak Adam, kayıp fonksiyonu olarak ise yüz ifadesi ve yaş sınıflandırma görevlerinde kategorik çapraz entropi, cinsiyet sınıflandırma görevinde ise ikili çapraz entropi kullanılmıştır. Öğrenme oranı 1e-3 olarak kullanılırken, ESA mimari tasarımları 50 epok boyunca eğitilmiştir. Küme boyutu ise yüz ifadesi, yaş ve cinsiyet sınıflandırma görevlerinde sırası ile 16, 64 ve 64 olarak kullanılmıştır. Önerilen ESA mimari tasarımlarında düzleştirme katmanından sonra sınıflandırma işleminin yapılabilmesi için tam bağlantı katmanları kullanılmıştır. Tam bağlantı katmanlarında kullanılan nöron sayısı sırasıyla 128 ve sınıf sayısı (yüz ifadesi, yaş ve cinsiyet sınıflandırma görevlerinde sırasıyla 7, 4 ve 2 ) kadardır. Tam bağlantı katmanlarında aktivasyon fonksiyonu olarak ise sırasıyla ReLu ve Softmax kullanılmıştır. Ek olarak tam bağlantı katmanları arasında 0.3 eşik değerinde seyreltme katmanı kullanılmıştır. ESA mimari tasarımlarına ait ağırlık dosyaları gerçek zamanlı analizde kullanılmak amacıyla kaydedilmiştir. Deneysel analizde NVIDIA GeForce GTX950M ekran kartı üzerinde Keras kütüphanesi kullanılmıştır. Tümleşik geliştirme ortamı (IDE) olarak ise Spyder tercih edilmiştir.

\subsection{Performans Değerlendirme Metrikleri}

Doğru Pozitif (TP), Doğru Negatif (TN), Yanlış Pozitif (FP), Yanlış Negatif (FN) değerleri sırayla; doğru sınıflandırılan pozitif sınıf sayısını, doğru sınıflandırılan negatif sınıf sayısını, yanlış sınıflandırılmış pozitif sınıf sayısını ve yanlış sınıflandırılmış negatif sınıf sayısını ifade etmektedir.

$$
\begin{aligned}
& \text { Doğruluk }=\frac{\mathrm{TP}+\mathrm{TN}}{\mathrm{TP}+\mathrm{FP}+\mathrm{TN}+\mathrm{FN}} \\
& \text { Kesinlik }=\frac{\mathrm{TP}}{\mathrm{TP}+\mathrm{FP}} \\
& \text { Duyarlılık }=\frac{\mathrm{TP}}{\mathrm{TP}+\mathrm{FN}} \\
& \text { F1-skor }=\frac{2 \times \text { Kesinlik } \times \text { Duyarlıllk }}{\text { Kesinlik+Duyarlılık }}
\end{aligned}
$$

Bu çalışmada kullanılan ESA modellerinin performansları, doğruluk oranı ve F1-skoru metriklerine göre ele alınmıştır. Elde edilen doğruluk oranları ve F1-skoru değerleri, karşılaştırmalı analiz ile birlikte bölüm 4'te sunulmuştur. 


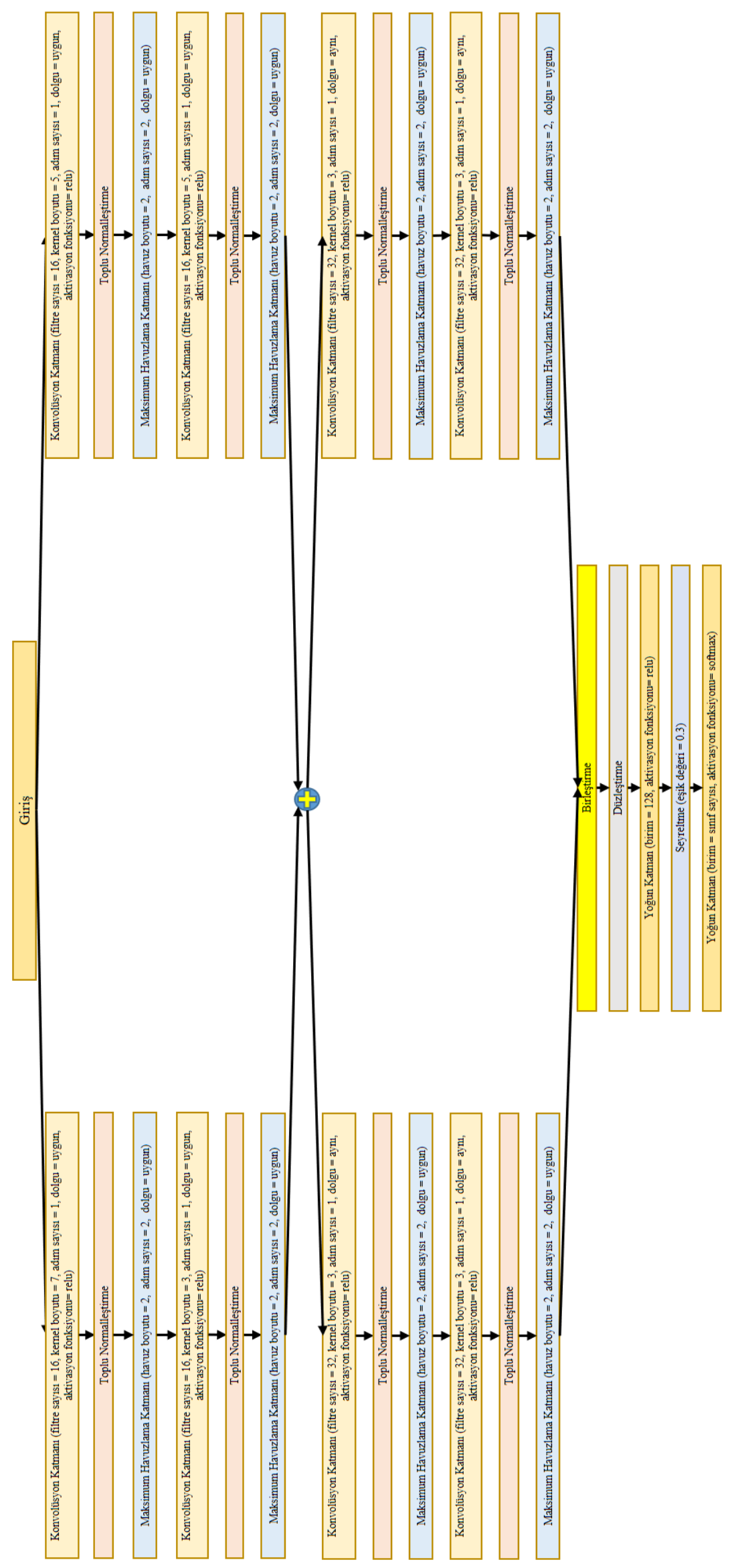

Şekil 4. ESA mimari tasarımı 1 


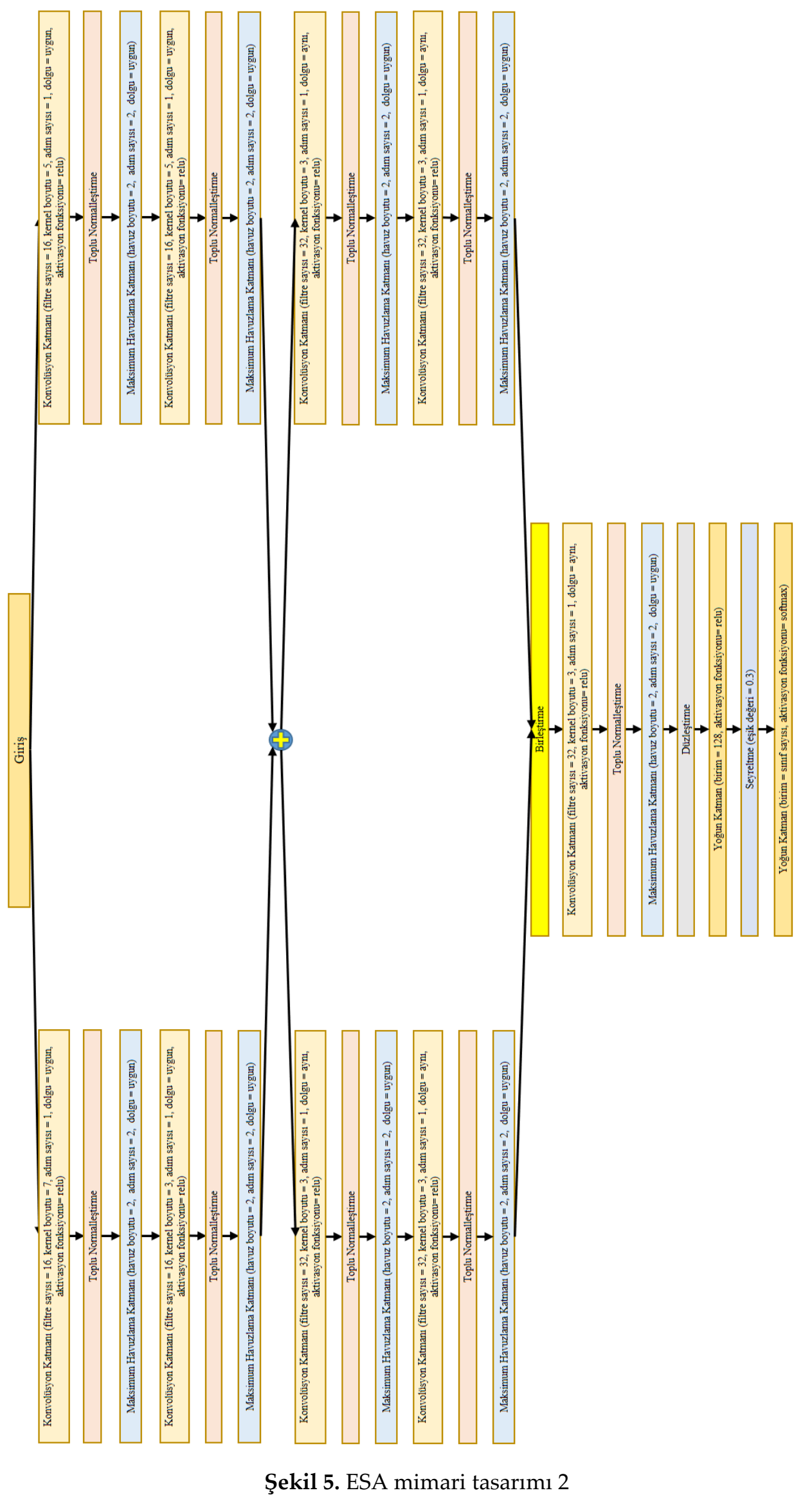




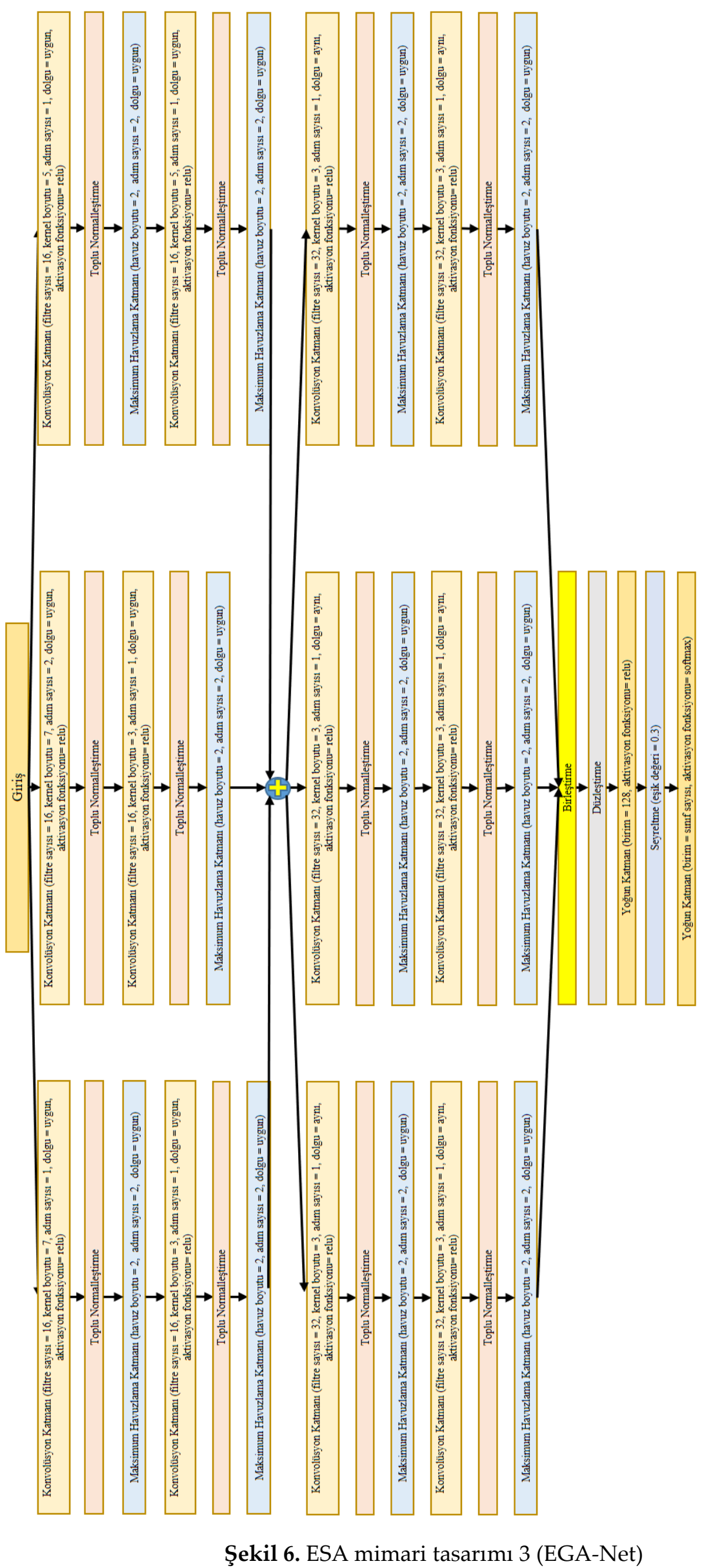




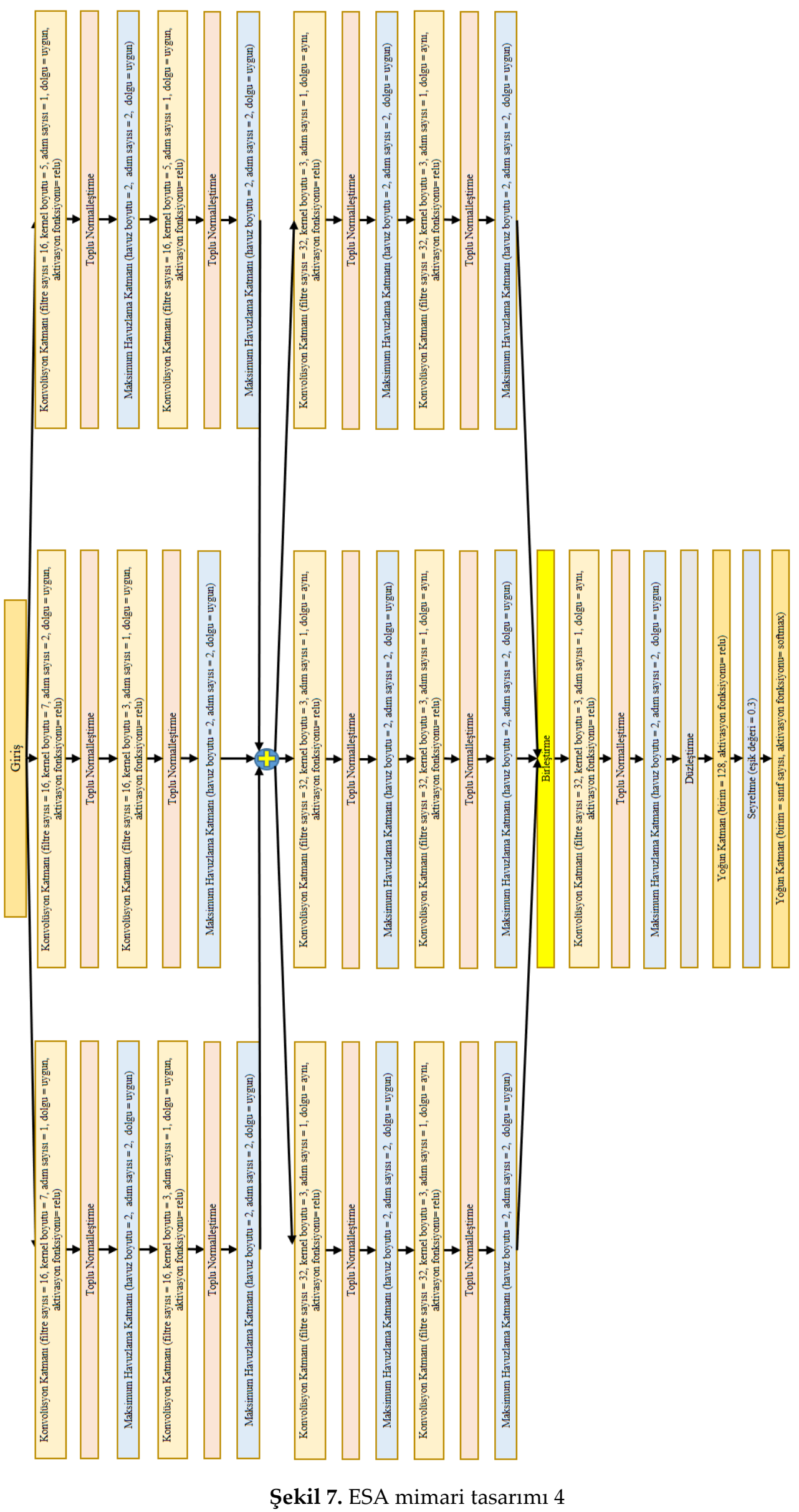




\section{Deneysel Çalışmalar ve Analizler}

Bu bölümde, ESA mimari tasarımları ile elde edilen doğruluk oranı ve F1-skoru sonuçlarına ek olarak ESA mimari tasarımları tarafından incelenen parametre sayıları yaş, cinsiyet ve yüz ifadesi sınıflandırma görevleri için sırasıyla Tablo 1, Tablo 2 ve Tablo 3'te gösterilmiştir.

Yaş sınıflandırma görevine ait değerlendirmeler aşağıda özetlenmiştir;

1.032.740, 162.500, 1.547.252 ve 190.612 parametre sirasiyla ESA mimari tasarımı 1, ESA mimari tasarımı 2, ESA mimari tasarımı 3 ve ESA mimari tasarımı 4 tarafından incelenmiştir. ESA mimari tasarımı 1, ESA mimari tasarımı 2, ESA mimari tasarımı 3 ve ESA mimari tasarımı 4 tarafından sırasıyla $\% 76.64, \% 77.56, \% 78.68$ ve $\% 75.72$ doğruluk oranı, $\% 64.18, \% 64.35, \% 66.89$ ve $\% 62.10$ F1-skoru sonuçları elde edilmiştir. Önerilen ESA modelleri tarafından elde edilen en iyi başarım performansları sırasıyla ESA mimari tasarımı 3 (\%78.68 doğruluk oranı ve \%66.89 F1-skoru), ESA mimari tasarımı 2 (\%77.56 doğruluk oranı ve \%64.35 F1-skoru), ESA mimari tasarımı 1 (\%76.64 doğruluk oranı ve \%64.18 F1-skoru) ve ESA mimari tasarımı 4 (\%75.72 doğruluk oranı ve \%62.10 F1-skoru) şeklindedir. Doğruluk oranları ile F1-skoru sonuçların birbirine yakın değerler ile elde edilememesinin nedeni Şekil 3 (b)'de gösterildiği gibi sınıflardaki yaş dağılımının dengesizliği ile açıklanabilir.

Tablo I. Yaş analizi görevinde önerilen ESA mimari tasarımları ile elde edilen doğruluk oranı ve F1skoru değerleri

\begin{tabular}{|c|c|c|c|}
\hline Model & Doğruluk Oranı & F1-skoru & İncelenen Parametre Sayıs1 \\
\hline ESA mimari tasarımı 1 & 0.7664 & 0.6418 & 1.032 .740 \\
\hline ESA mimari tasarımı 2 & 0.7756 & 0.6435 & 162.500 \\
\hline ESA mimari tasarımı 3 (EGA-Net) & $\mathbf{0 . 7 8 6 8}$ & $\mathbf{0 . 6 6 8 9}$ & $\mathbf{1 . 5 4 7 . 2 5 2}$ \\
\hline ESA mimari tasarımı 4 & 0.7572 & 0.6210 & 190.612 \\
\hline
\end{tabular}

Cinsiyet sınıflandırma görevine ait değerlendirmeler aşağıda özetlenmiştir;

1.032.482, 162.242, 1.546.994 ve 190.354 parametre sirasiyla ESA mimari tasarımı 1, ESA mimari tasarımı 2, ESA mimari tasarımı 3 ve ESA mimari tasarımı 4 tarafından incelenmiştir. ESA mimari tasarımı 1, ESA mimari tasarımı 2, ESA mimari tasarımı 3 ve ESA mimari tasarımı 4 tarafından sırasıyla $\% 84.41, \% 84.76, \% 84.51$ ve $\% 85.02$ doğruluk oran1, $\% 84.10, \% 84.36, \% 84.34$ ve $\% 84.85$ F1-skoru sonuçları elde edilmiştir. Önerilen ESA modelleri tarafından elde edilen en iyi başarım performansları sırasıyla ESA mimari tasarımı 4 (\%85.02 doğruluk oranı ve \%84.85 F1-skoru), ESA mimari tasarımı 2 (\%84.76 doğruluk oranı ve \%84.36 F1-skoru), ESA mimari tasarımı 3 (\%84.51 doğruluk oranı ve \%84.34 F1-skoru) ve ESA mimari tasarımı 1 (\%84.41 doğruluk oranı ve \%84.10 F1-skoru) şeklindedir.

Yüz ifadesi sınıflandırma görevine ait değerlendirmeler aşağıda özetlenmiştir;

1.033.127, 162.887, 1.547.639 ve 190.999 parametre sırasiyla ESA mimari tasarımı 1, ESA mimari tasarımı 2, ESA mimari tasarımı 3 ve ESA mimari tasarımı 4 tarafından incelenmiştir. ESA mimari tasarımı 1, ESA mimari tasarımı 2, ESA mimari tasarımı 3 ve ESA mimari tasarımı 4 tarafından sırasıyla \%94.92, \%93.91, \%99.49 ve \%98.07 doğruluk oranı, \%93.33, \%95.82, \%99.68 ve \%97.95 F1-skoru sonuçları elde edilmiştir. Önerilen ESA modelleri tarafından elde edilen en iyi başarım performansları sırasıyla ESA mimari tasarımı 3 (\%99.49 doğruluk oranı ve \%99.68 F1-skoru), ESA mimari tasarımı 4 (\%98.07 
doğruluk oranı ve \%97.95 F1-skoru), ESA mimari tasarımı 1 (\%94.92 doğruluk oranı ve \%93.33 F1-skoru) ve ESA mimari tasarımı 2 (\%93.91 doğruluk oranı ve \%95.82 F1-skoru) şeklindedir.

Tablo 2. Cinsiyet sınıflandırma görevinde önerilen ESA mimari tasarımları ile elde edilen doğruluk oranı ve F1-skoru değerleri

\begin{tabular}{|c|c|c|c|}
\hline Model & Doğruluk Oranı & F1-skoru & İncelenen Parametre Sayısı \\
\hline ESA mimari tasarımı 1 & 0.8441 & 0.8410 & 1.032 .482 \\
\hline ESA mimari tasarımı 2 & 0.8476 & 0.8436 & 162.242 \\
\hline ESA mimari tasarımı 3 (EGA-Net) & 0.8451 & 0.8434 & 1.546 .994 \\
\hline ESA mimari tasarımı 4 & $\mathbf{0 . 8 5 0 2}$ & $\mathbf{0 . 8 4 8 5}$ & 190.354 \\
\hline
\end{tabular}

Tablo 3. Yüz ifadesi analizi görevinde önerilen ESA mimari tasarımları ile elde edilen doğruluk oranı ve F1-skoru değerleri

\begin{tabular}{|c|c|c|c|}
\hline Model & Doğruluk Oranı & F1-skoru & İncelenen Parametre Sayıs1 \\
\hline ESA mimari tasarımı 1 & 0.9492 & 0.9333 & 1.033 .127 \\
\hline ESA mimari tasarımı 2 & 0.9391 & 0.9582 & 162.887 \\
\hline ESA mimari tasarımı 3 (EGA-Net) & $\mathbf{0 . 9 9 4 9}$ & $\mathbf{0 . 9 9 6 8}$ & 1.547 .639 \\
\hline ESA mimari tasarımı 4 & 0.9807 & 0.9795 & 190.999 \\
\hline
\end{tabular}

Yaş, cinsiyet ve yüz ifadesinin sınıflandırılması görevlerinde, en iyi performansın elde edildiği ESA mimari tasarımlarına ait ağırlık dosyaları gerçek zamanlı analiz aşamasında kullanılmıştır. Elde edilen gerçek zamanlı sonuçlar Şekil 8'de gösterilmiştir. Bu aşamada OpenCV kütüphanesi gerçek zamanlı kamera görüntüsünün alınmasında kullanılmıştır.

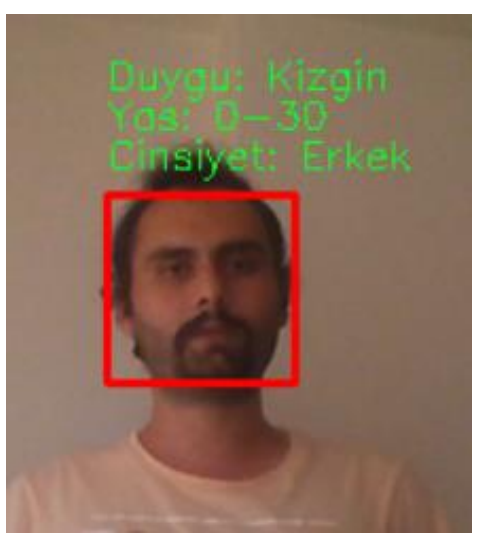

Şekil 8. Gerçek zamanlı olarak elde edilen yaş, cinsiyet ve yüz ifadesi analizi sonucu 


\section{Sonuç}

Genel analizde, giriş görüntülerinin üç paralel bloğa verildiği ESA mimari tasarımları olan 3 ve 4, giriş görüntülerinin iki paralel bloğa verildiği ESA mimari tasarımları olan 1 ve 2 'den daha iyi sinıflandırma performansı elde etmiştir. Cinsiyet, yaş ve yüz ifadesi sınıflandırma olmak üzere üç görevin ikisinde en iyi sınıflandırma performansını elde eden ESA mimari tasarımı 3, EGA-Net olarak adlandırılmıştır. Konvolüsyon katmanları ile elde edilen özellik haritasının birleştirilmesinden sonra kullanılan konvolüsyon ve maksimum havuzlama katmanlarını içeren blok incelenen parametre sayısını azaltmıştır. Bu mimari yapının kullanımı ile birlikte cinsiyet sınıflandırma görevinde tahmin performansı artırmıştır, yüz ifadesi sınıflandırma görevinde tahmin performansı azalmıştır, yaş sınıflandırma görevinde ise iki paralel bloktan oluşan mimari tasarımda tahmin performansı artarken üç paralel bloktan oluşan mimari tasarımda tahmin performansı azalmıştır. Tahmin performansındaki azalmaya rağmen modelin eğitim süresinin kısalması dikkate alındığında, birleştirilme katmanından sonra kullanılan konvolüsyon, toplu normalleştirme, maksimum havuzlama katmanlarını içeren bloğun yer aldığı mimari tasarımların da kullanılabilirliği yüksektir. Sonuç olarak bu çalışmada, ESA mimari tasarımlarına dayalı olarak uçtan uça yapıda oluşturulan ve üretim çalışanlarının yaş, cinsiyet ve ifadelerinin analizinin gerçek zamanlı olarak yapılmasını sağlayan bir karar destek sistemi geliştirilmiştir.

\section{Teşekkür}

Bu çalışma, İzmir Katip Çelebi Üniversitesi Bilimsel Araştırma Projeleri Koordinatörlüğü, Proje no: 2021-TYL-FEBE-0009 tarafından desteklenmiştir.

\section{Kaynaklar}

Levi G, Hassncer T. (2015) Age and gender classification using convolutional neural networks. IEEE Computer Society Conference on Computer Vision and Pattern Recognition Workshops, 2015Octob, pp. 34-42.

Abdolrashidi A, Minaei M, Azimi E ve Minaee S (2020) Age and Gender Prediction From Face Images Using Attentional Convolutional Network. arXiv preprint arXiv:2010.03791.

Özbulak G, Aytar Y ve Ekenel HK. (2016) How transferable are CNN-based features for age and gender classification?. International Conference of the Biometrics Special Interest Group (BIOSIG), pp. 1-6.

Söylemez ÖF, Ergen B (2020) Farklı Evrişimsel Sinir Ağı Mimarilerinin Yüz İfade Analizi Alanındaki Başarımlarının İncelenmesi. DÜMF Mühendislik Dergisi 11(1): 123-133.

Pitaloka DA, Wulandari A, Basaruddin T ve Liliana DY (2017) Enhancing CNN with Preprocessing Stage in Automatic Emotion Recognition. Procedia Computer Science 116: 523-529.

CKPLUS I Kaggle. (n.d.). https://www.kaggle.com/shawon10/ckplus. Accessed June 15, 2021.

UTKFace I Kaggle. (n.d.). https://www.kaggle.com/jangedoo/utkface-new. Accessed August 1, 2021. 